\title{
Indigenous Perception of Cultural Heritage and its Man- agement: a Cursory Blue-print Among the Senufo in the Sikasso Region of Mali
}

\author{
Sekou Berte \\ Institute of Archaeology, UCL.
}

Data collection during April and June 2001in the Sikasso region of southern Mali, West Africa, proved to be a journey of self-discovery, both from an individual and communal perspective. My fieldwork was primarily aimed at understanding how the indigenous Senufo perceive and manage their cultural heritage. Despite a long history of cultural contact, these peoples are found to be culturally heterogeneous, adhering to strong traditions and claiming common cultural identity. Given these continuing cultural traditions, my position as a community member placed me in a unique position to provide useful insights regarding both the processes of establishing and/or assessing cultural identities over time and the understanding of local material culture from an indigenous perspective. The methodological approach therefore, consisted of meshing indigenous Senufo knowledge with archaeological evidence to attempt a cursory blueprint of the archaeological landscape of the Senufo inhabited area. The following report will aim to introduce the reader to some of the social dynamics underpinning this study and some preliminary results.

\section{Introduction}

It has been argued by a number of scholars that the conceptualisation of the past continually anchors peoples to variable debates, irrespective of status and cultural backgrounds (Lowenthal 1985; McBride 1995; Schmidt and McIntosh 1996; Ucko 2000). Yet, although this does appear as a constant dynamic cross-culturally, the control of the globally widespread modes of access to the past such as history and prehistory remain a chasse gardée (vanguard) of a westernised mainstream of 'experts' i.e. scholars, and cultural resource brokers (Cleere 1989; Hartley 1997;Layton 1994; Lertrit 1997; Pwiti 1996; Shackley 1997). Historical and prehistoric accounts of the past draw upon scholarly contributions and remain by and large moulded by representations, which are in turn, partly impacted on by antiquarianism. Overall, the process seems to have made little or no attempt to consider alternative options, namely local viewpoints, which can potentially open up wider understanding for discourses on the past (Ki-Zerbo 1981; Vansina 1985).

In Mali, as elsewhere, the widespread trends of debates have long ignored indigenous perspectives on the past and heritage studies. Archaeological involvement shows a long established legacy in northern parts of the country (Raimbault and Sanogo 1991; Sanogo 2000). By comparison, other regions, such as western and northwestern parts, have received only episodic attention, whilst only the northern areas of the southern region have ever undergone any archaeological research. Cultural Missions, conceived to ensure the safeguarding of heritage places and resources have been enhancing local involvement in the Inland Niger Delta and parts of the 
northern regions in Mali since the early 1990s. In addition, a three-year project aimed at instrumental experimentation of integrated and sustainable protection has been initiated in the realm of heritage studies and management. Yet until now, an impact study, which can provide insights into this ambitious experimentation, has never been attempted (Diaby and Sanogo 2000; Sanogo 2001 pers. comm.). In contrast to previous scholarly works in the region, my fieldwork consists of the novel approach of combining archaeological research and ideological constructs of the past from indigenous perspectives.

\section{Objectives of the Fieldwork}

Broadly, the aims of the fieldwork fall into two levels: understanding and analysing the indigenous perception of cultural heritage among the Senufo people of the Sikasso region, and attempting an integration of conceptual approaches (both Senufo and academic) for the evaluation of archaeological and/or cultural resources among the Senufo. More specifically, the study aims at the following:

- Understanding how Senufo people define cultural resources.

- Identifying, locating and documenting archaeological sites.

- Documenting how the knowledge of the past is used in solving conflicts.

- Documenting access to and control of cultural heritage.

- Assessing the present state of preservation of cultural heritage in the Senufo region and the impact of merely passive care for cultural relics.

- Exploring how to suggest managerial strategies to stop destruction of cultural heritage or to alter passive care.

\section{Methodology}

The field survey took place in three study zones: the Kadiolo area (including southern Senufo territories, bordering Cote d'Ivoire); Sikasso and its environs (central Senufo lands); and the Dogoni area (comprising the extreme northern Senufo territories). The choice of these study zones aimed to most effectively integrate (from an indigenous perspective) a picture of the Senufo archaeological and cultural landscapes, focusing on the human-geographical concentration zone of Senufo people in Mali. The villages of Watialy, Mpela, Sokurani and Misirikoro were selected from the three study zones. The latter two villages claimed ownership rights over one important surveyed rock-shelter site, Misirikoro. During my survey, I followed parts of the trade routes dating from the early $15^{\text {th }}$ century across the study region (BelecoSikasso and Sikasso-Tengrela-Khong) to gain a picture of the landscape of contact sites. I made frequent stops at different types of sites, such as tells and looted tumuli, to further explore the archaeological landscape.

As pointed out earlier, the methodological approach consisted of meshing Senufo definition of sites and archaeological evidence. Field walking was instrumental in identifying, locating and documenting the archaeological landscape. Basic archaeological techniques were used to document both sites and artefacts. In Watialy for example (study zone one), four sites of iron ore extraction, three sites of iron furnaces, hypogea sites, three rock art sites, and the south-western part of a city wall predating the $18^{\text {th }}$ century, were recorded. The documentation process also included opportunistic surveys and guided exploration of both cultural and archaeological 
landscapes, to better match oral information with mapping and photography. Additionally, archaeological sites that seem to be significant for the Senufo were documented.

Interviews were conducted with 'tradition bearers' (village elders and other representatives) from variable socio-cultural backgrounds about the social significance of archaeological sites and the management of cultural resources. Village assemblies were organized and the villagers themselves chose the informants from a wide range of age groups of several generations. This allowed the gathering of different viewpoints on cultural heritage issues. Archival information on the human-geographical distribution of Senufo communities and their material culture was collated from institutions in London, Bamako and Sikasso.

\section{Results}

Overall, the fieldwork activities led to what might be best described as a reconstruction of a votive archaeological landscape, which is viewed as sacred in its entirety by the Senufo. The land is namely seen as a holy landscape, under temporal and spatial control of both ancestors and spirits. By contrast, the archaeological landscape is defined by the Senufo as that of a cultural locus of ancient events, things, and places. Indeed, the Senufo classify archaeological sites according to generic terminology. Among the Senufo, heritage sites and/or archaeological sites are termed as Kataalie $y i$ or kataalicye. Both these generic terms can be used interchangeably to stand for ancient settlement tells and other human activity areas making use of the natural landscape. Literally, these terms designate places of earlier events, things, and manmade and/or integrated natural features. Individual sites are defined according to their inherent past and present functional roles. For example faasiike and tuwolwieegbe stand respectively for agriculture lands and iron ore extraction holes/open but disused mines. In a broader sense, sites are those areas known for both natural and man-made heritage. Several types of sites were documented. Yet, the types of sites that seemed mostly significant for the Senufo, historically and ideologically were the following:

- Settlement tells.

- Rock-art sites.

- Sacred groves and shrines.

- Iron production sites.

- Sacred reserves (natural and man-made environment).

- City walls (in Siama, Watialy and Sikasso).

- Cemeteries (characterised by the presence of hypogea, with their prominent architectural features).

- Natural reserve associated with duppies (wandering spirits of non-identified individuals).

Because of the cursory nature of the survey, it is difficult to establish any definitive patterns of access to and control of these resources. Moreover, it is hard to posit cultural change at two levels. Without a clearer understanding of the chronological developments and origins of specific cultural canons, archaeological interpretation lacks a temporal human-geographical framework. Nevertheless, it can be observed 
throughout the study area, that the archaeology in the Senufo inhabited area is circumscribed by a globally changing world and the dynamics of cultural contact. The local archaeological landscape concentrates within a $50 \mathrm{~km}$ radius of each selected village territory.

\section{Discussion}

In each of the study areas, archaeological (and culturally important natural) sites are embedded within common folk memory. Across the study region, the perceived archaeological sites operate as cultural loci, associated not only with the occupational and ancestral identity but also with supernatural agency and present sociocultural activities and meanings. These archaeological landscapes are characterised by artefacts, which are used by indigenous Senufo to ground corporate and individual claims over 'patrimony'. Two components can retain specific attention, one spiritual and the other political. For instance, settlement tells are constructs of cultural loci, within which people interact socio-culturally, as they are profoundly connected to the concept of common ownership, either for individual families and/or for communities at village and regional levels. These constructs are associated with ancestral figures and/or heroes and their belief systems.

The field survey contributed to the discovery of several new sites. These bring additional insights to archaeology, both at a regional and national level. Here it is noteworthy that these new sites are void of any modern management standard, as sites are actively used and subject to both natural and human pressure, such as erosion and agro-pastoral activities. The enthusiastic handling of the fieldwork activities also illustrates that, although it was the first time that locals ever had a chance to contribute to any archaeological involvement, indigenous Senufo would have been supportive of any activity that enhances our understanding of the prehistory in the area, and would have been more concerned about caring actively for their cultural heritage.

Future archaeological work and heritage management would benefit from sustainable and integrated conceptual approaches, with academia and indigenous Senufo, thereby providing a new page of prehistory that draws upon the contribution of both worldviews. Future research must also aim at a deeper integration of the indigenous conceptualisation of archaeological landscapes, as well as issues relating to the management of both archaeological and cultural resources, not only among the Senufo (and their neighbours) in Mali, but also in neighbouring West African countries, such as Burkina Faso, Cote d'Ivoire and Ghana.

\section{Acknowledgements}

I am very grateful to the Institute of Archaeology, UCL, not only for training, but also for the financial support that was offered for the completion of my MA degree and the fieldwork. Thanks also to the support from Institut des Sciences Humaines (ISH), National Centre for Scientific Research and Technology (CRNST) in Mali, and the local authorities and individuals at village and town levels. I am also indebted to my assistant Mr. Assimy Bengaly and my nephew Mr. Modibo Diallo, who helped with several tasks and errands during fieldwork. They genuinely endeavoured to make this research tour fruitful. 


\section{References}

Cleere, H. (ed.) 1989. Archaeological Heritage Management in the Modern World One World archaeology 9. London and New York: Routledge.

Diaby, B. H. and Sanogo K. 2000. Sauvegarde du patrimoine archéologique du Mali, in Vernet R. (ed.) L'Archéologie en Afrique De l'Ouest: Sahara et Sahel. Nouakchott, France: CRIAAEditions Sepia.

Hartley S. H. 1997. Is Shared Leadership An Oxymoron. CRM: Cultural Resource Management. Volume 20 (4), 6-8.

Ki-Zerbo, J. (ed.) 1981. General History of Africa. I: Methodology and African Prehistory. Berkeley: University of California Press.

Layton, R. 1989. (ed.) Conflict in the Archaeology of Living Traditions. London: Unwin.

Lertrit, S. 1997. Who Owns the Past? A Perspective from Chiang Saen, Thailand, in Conservation and Management of Archaeological Sites 2 (2), 81-92.

Lowenthal, D. 1985. The Past is a Foreign Country. Cambridge: Cambridge University Press.

McBride K. A. 1995. CRM and Native Americans, An Example from Mashantucket Pequot Reservation. CRM: Cultural Resource Management 18(3), 15-17.
Pwiti, G. 1996. Let the Ancestor Rest in Peace? New Challenges for Cultural Heritage Management in Zimbabwe. Conservation and Management of Archaeological Sites 1, 151-160.

Raimbault, M. and Sanogo, K. (eds.) 1991. Recherches Archéologiques au Mali. Paris: ACCT. Karthala.

Schmidt, P. R. and McIntosh, R. J. 1996. Plundering Africa's Past. Bloomington, Indiana: Indiana University Press.

Sanogo, K. 2000. Le Cadre Chronologique. in Archéologie en Afrique De l'Ouest: Sahara et Sahel. Robert Vernet (ed.). Nouakchott, France: CRIAA-Editions Sepia.

Shackley, M. 1997. Tourism and the Management of Cultural Resources in the Pays Dogon, Mali. International Journal of Heritage Studies 3 (1), 17-27.

Ucko, P. J. 2000. Enlivening a "Dead" Past. Conservation and Management of Archaeological Sites 4, 69-92

Vansina, J. 1985. Oral Tradition as History. London: James Curry and Heinemann. 